\title{
Effects, experiences, and impact of stigma on patients with bipolar disorder
}

This article was published in the following Dove Press journal:

Neuropsychiatric Disease and Treatment

15 January 2013

Number of times this article has been viewed

\section{Viktoria R Mileva' \\ Gustavo H Vázquez ${ }^{2}$ \\ Roumen Milev ${ }^{3}$}

'Psychology, School of Natural Sciences, University of Stirling, Stirling, UK; ' ${ }^{2}$ Department of Neurosciences, University of Palermo, Buenos Aires, Argentina; ${ }^{3}$ Department of Psychiatry, Queen's University, Kingston, ON, Canada

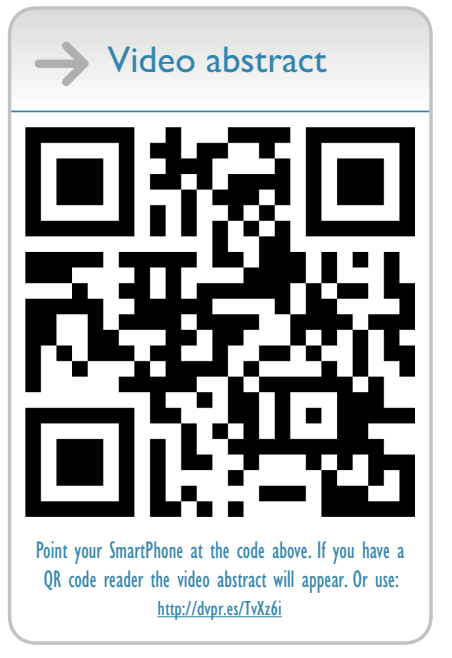

Correspondence: Roumen Milev Queen's University, Department of Psychiatry, 752 King Street West, Kingston, Ontario

K7L 4X3, Canada

$\mathrm{Tel}+\mathrm{I} 6 \mid 35485567$ ext 5823

Fax + I 6135485580

Email roumen.milev@queensu.ca
Background: Many people with mental illness experience stigma that has impacted their lives. In this study, we validated the Inventory of Stigmatizing Experiences (ISE) as a tool to help quantify the stigma experienced by patients with bipolar disorder and its impact on their lives. The ISE has two components, ie, the Stigma Experiences Scale (SES) and the Stigma Impact Scale (SIS), which were administered to a population of Argentinean patients with bipolar disorder. We characterized the differences between these two populations using the SES and SIS. Finally, we compared SES and SIS scores with those in a population of Canadian patients with bipolar disorder.

Methods: The SES and SIS scales were administered to tertiary care patients with bipolar I and II disorder in Argentina $(\mathrm{n}=178)$ and Canada $(\mathrm{n}=214)$

Results: In this study, we validated both SES (Kuder-Richardson coefficient of reliability, 0.78) and SIS (Cronbach's alpha, 0.91) scales in a population of Argentinean patients with bipolar disorder. There were no significant differences in stigma between patients with bipolar I or II disorder on SES or SIS. However, over $50 \%$ of all respondents believed that the average person is afraid of those with mental illnesses, that stigma associated with mental illness has affected their quality of life, and that their self-esteem has suffered due to stigma. In comparison with the Canadian population, Argentinean participants scored lower on both the SES and SIS, which may be due to cultural differences or to differences in population characteristics.

Conclusion: Stigma associated with mental illness is serious and pervasive. If we are to find successful strategies to mitigate stigma, it is first important to understand how patients perceive such stigma. The ISE is a valuable tool which allows us to do this with high reliability among cultures

Keywords: stigma, bipolar disorder, scale, experiences, impact, Inventory of Stigmatizing Experiences

\section{Introduction}

Feeling stigmatized is common among those living with mental illness. ${ }^{1-5}$ Around the world many people with mental illness are discriminated against, have restricted work opportunities, feel stigmatized at work, ${ }^{6-8}$ and are even denied the basic rights afforded to other members of society. ${ }^{9}$ Where studies have been conducted in the Western world, it appears that the majority of the public, ${ }^{3,10}$ from children and adolescents, ${ }^{11}$ to mental health professionals, ${ }^{12-14}$ and even family members ${ }^{15}$ hold stigmatizing attitudes towards those with mental illnesses. Understandably, this social derision and intolerance may produce feelings of helplessness, apathy, denial, and shame in those affected. 5,8,16,17 Recent research even shows that social stigma can be internalized, 
whereby a person starts to believe that the social stigma is an accurate reflection of themselves, and this self-stigma is evident in many patients with severe mental illness. ${ }^{18-20}$ For some or all of these reasons, a person with a mental illness may be less likely to seek treatment and/or have an increased likelihood of relapse,,$^{2,21-23}$ in effect aiding the perpetuation of social stigma. ${ }^{5}$

Within the last two decades, combating and reducing worldwide stigma towards mental illness has become a major movement in the field of psychiatry. This has led ultimately to the development of international programs designed to raise awareness and to find ways of remedying the problem. The Global Program to Fight Stigma and Discrimination Because of Schizophrenia, more commonly known as the "Open-the-Doors" program, as well as the World Psychiatric Association's “Scientific Section on Stigma and Mental Health" are two major undertakings around the world working towards this end. ${ }^{24,25}$ Over 21 countries are now part of this network, with large, multilevel initiatives designed to bring awareness and understanding of mental illnesses to the public, in an effort to reduce stigma. ${ }^{24,25}$

Although these programs and initiatives are rooted in combating the widespread social stigma which exists regarding schizophrenia, ${ }^{26,27}$ a general discriminatory attitude is persistent with most mental illnesses. ${ }^{28}$ Bipolar disorder is a common ${ }^{29}$ debilitating mental illness associated with significant burden, ${ }^{30}$ and is among the top ten leading causes of disability worldwide. ${ }^{8}$ Therefore, in this study, we aimed to look at the social stigma surrounding bipolar disorder (both I and II) in a cross-cultural manner. Few studies have looked at stigma in patients with bipolar disorder, but there is recent evidence to suggest that they are stigmatized in society, ${ }^{15,26,31}$ and that these patients perceive themselves as being stigmatized. ${ }^{32-34}$ Clearly, this can affect their recovery. ${ }^{35}$ In patients exhibiting acute symptoms, those who were more concerned about the effects of stigma were also more likely to report impaired social adjustment 7 months later, compared with those who viewed stigma as less important in their lives. ${ }^{35}$

Consequently, while education of the public is imperative in the long-term goals towards ending stigma, it is also vital to uncover the extent to which persons dealing with mental illness are affected, and what impact this has on their lives and daily functioning. In this study, we used a standardized questionnaire, ie, the Inventory of Stigmatizing Experiences (ISE) which documents both a person's experiences with stigma using a Stigma Experiences Scale (SES) and the impact this stigma has had on their lives using a Stigma Impact Scale (SIS), as well as general social characteristics. ${ }^{4,34}$ The ISE appears to be a reliable and valid inventory of stigma, and can be used as an effective tool in measuring stigma from a patient's perspective.

The goals of this study were essentially three-fold: to validate the ISE for a population of patients with bipolar I or II disorder living in Argentina; to identify differences in the experiences and impact of stigma between patients with bipolar I or II disorder using standardized ISE measures; and to compare the results obtained in this Argentinean population with those in a Canadian population of patients with bipolar disorder, ${ }^{34}$ in an effort to uncover any cross-cultural differences.

We hypothesized that patients with bipolar I disorder would be impacted more from stigma than those with bipolar II disorder due to the presence of manic or mixed episodes in those suffering from bipolar I disorder. A recent study found that there was significantly more caregiver stigma toward patients with bipolar I disorder. ${ }^{15}$ Additionally, we hypothesized that while the Argentinean population may experience similar stigmatizing events, they may not be as impacted as the Canadian population, perhaps due to the greater role of family care and support found in Latin American countries (similar to Spain). In a cross-cultural study of European countries, Spaniards with bipolar disorder reported feeling less stigmatized than patients with bipolar disorder in other European countries, including France, The Netherlands, and Scotland. ${ }^{33}$ The authors do not make inferences from their data as to why this might be the case; however, it is possible that cultural differences play a role. Additionally, the sample was younger, with relatively low unemployment, and had more access to psychoeducation in comparison with the other countries studied. We predicted that we would find less stigma in the Argentinean population as compared with the Canadian population.

\section{Materials and methods \\ Patient population}

The Argentinean sample comprised a total of 178 participants with bipolar disorder. They were recruited through an outpatient research program of the Argentine Network for Bipolar Disorders which includes 11 specialized third level mood disorder clinics throughout Argentina. The centers included five public psychiatric hospitals (two in Buenos Aires, and one each in Cordoba, Formosa, and Jujuy) and six private outpatient clinics (three in Buenos Aires, and one 
each in La Plata, Mar del Plata, and Mendoza). A diagnosis of bipolar I or II disorder was established using the Structured Clinical Interview for Diagnostic and Statistical Manual of Mental Disorders, 4th Edition (DSM-IV), Patient Edition, administered by psychiatrists experienced in affective disorders. Exclusion criteria included age less than 18 years, any significant medical illnesses, severe Axis II personality disorder, presence of suicide risk at the time of evaluation, and substance abuse disorder as the primary diagnosis. All patients met the clinical criteria for euthymia, defined as a score $\leq 9$ on the Young Mania Rating Scale score and a score $\leq 12$ on the 17-item Hamilton Depression Rating Scale at the time of assessment.

Canadian subjects were recruited from tertiary care facilities in Kingston, Canada. The Canadian component of this study was drawn from a population of patients whose demographic information has been published in a recent study. ${ }^{34}$ Briefly, this population was a convenience sample and all participants meeting the DSM-IV criteria for bipolar disorder were included. After a full description of the study procedures, written informed consent was provided by all subjects. The study was approved by the institutional review boards of the study sites.

\section{Measures}

Based upon previous work, ${ }^{4}$ participants in Argentina were asked to complete a translated version of the ISE, including the SES and SIS. The complete inventory was translated from English into Spanish by one of the authors (GV). Using professional Argentinean translators, this Spanish version was then back translated, ${ }^{36}$ and subsequently approved by one of us (GV). This translated scale has also been used and published recently, ${ }^{31}$ and in our study was administered to patients in the form of interviews or take-home pages.

\section{Statistical analysis}

All statistical analyses were conducted on PASW version 18 for Windows (IBM Corporation, Armond, NY). Measures to test internal consistency were performed for both SES and SIS using the Kuder-Richardson coefficient of reliability (KR-20) and Cronbach's alpha reliability coefficient, respectively. Chi-square analyses were completed on frequency scores (gender, level of highest education, employment, marital status, frequency of outpatient care, and acceptance of diagnosis), while $t$-tests or Mann-Whitney $U$ tests were performed on mean scores (age, number of years ill, years between first symptoms and treatment, and in assessing differences between SES and SIS scores). Where data were not normally distributed and did not have equal variance, nonparametric tests were performed. A two-step forced entry multiple regression was also performed (using variables which differed significantly between the two populations as predictor variables) in order to examine systematic differences between SES and SIS scores in the Canadian and Argentinean patient populations.

\section{Results \\ Social characteristics of participants}

Of the 178 Argentinean participants, 64\% were female, all were aged $18-83$ years, approximately $56 \%$ had a university education, $61 \%$ were employed, and $38 \%$ were married or in a common law relationship (Table 1). Further, 35\% lived with a spouse or partner, $72 \%$ thought that their condition had improved over the last year, over $40 \%$ had been ill for less than 10 years, and an overwhelming proportion (about 85\%) had come to accept their diagnosis (Table 1). The respondents were further subdivided into those with bipolar I and those with bipolar II disorder (Table 1). Similar data were obtained for Canadian participants. ${ }^{34}$

\section{Validation of SES and SIS measures}

In total, 141 of the 178 Argentinean participants originally recruited answered all 10 SES scale questions. Over half of these $(61.7 \%)$ endorsed the question that the average person is afraid of someone with a serious mental illness (Table 2). The mean score for this scale was 4.5 , with a high KR-20 (0.78). One question pertaining to avoidance of stigmatizing situations had an item-rest correlation under 0.4 , but when the variable was deleted, it did not significantly change the KR-20 and was kept in the analysis (Table 2).

A total of 160 participants responded to every item on the seven-question SIS scale. The mean scale score was 29.1, with a Cronbach's alpha reliability coefficient of 0.91 (Table 3). It appeared that stigma most strongly affected one's self esteem (mean of 5.2), while the lowest affected characteristic was social contacts of family members, at a mean of 3.0 (Table 3).

\section{Comparison of SES and SIS in bipolar I and II participants}

Mean SES scores for patients with bipolar I (4.5) and bipolar II (4.4) disorder did not differ significantly ( $t$-test, $\mathrm{t}_{139}=0.18, P=0.86$, Table 2). Mean SIS scores for patients 
Table I Demographic characteristics of sample population

\begin{tabular}{|c|c|c|c|}
\hline Characteristic & Bipolar I \% (n) & Bipolar II \% (n) & Total \% (n) \\
\hline \multicolumn{4}{|l|}{ Gender } \\
\hline Male & $39.6(36)$ & $31.4(27)$ & $35.6(63)$ \\
\hline Female & $60.4(55)$ & $68.6(59)$ & $64.4(114)$ \\
\hline \multicolumn{4}{|l|}{ Age group (years) } \\
\hline$>20$ & $2.2(2)$ & $2.3(2)$ & $2.2(4)$ \\
\hline $20-29$ & $16.3(15)$ & $15.1(13)$ & $15.7(28)$ \\
\hline $30-39$ & $25.0(23)$ & $22.1(19)$ & $23.6(42)$ \\
\hline $40-49$ & $28.2(26)$ & $19.8(17)$ & $24.2(43)$ \\
\hline $50-59$ & $19.6(18)$ & $32.6(28)$ & $25.8(46)$ \\
\hline $60-69$ & $8.7(8)$ & $7.0(6)$ & $7.9(14)$ \\
\hline$>80$ & 0 & I.I (I) & $0.6(I)$ \\
\hline \multicolumn{4}{|l|}{ Highest education } \\
\hline Public school or less & $5.6(5)$ & $7.1(6)$ & $6.3(\mathrm{II})$ \\
\hline High school & $25.8(23)$ & $27.0(23)$ & $26.5(46)$ \\
\hline College or technical training & $7.9(7)$ & $15.3(13)$ & II.5 (20) \\
\hline University & $60.7(54)$ & $50.6(43)$ & $55.7(97)$ \\
\hline \multicolumn{4}{|l|}{ Employment status } \\
\hline Employed & $60.7(54)$ & $6 \mathrm{I} .4(5 \mathrm{I})$ & $61.0(105)$ \\
\hline Unemployed & $39.3(35)$ & $38.6(32)$ & $39.0(67)$ \\
\hline \multicolumn{4}{|l|}{ Marital status } \\
\hline Single & $60.0(54)$ & $64.0(55)$ & $61.9(109)$ \\
\hline Married/common law & $40.0(36)$ & $36.0(31)$ & $38.1(67)$ \\
\hline \multicolumn{4}{|l|}{ Living situation } \\
\hline Alone & |3.3 (I2) & $16.3(14)$ & | $4.8(26)$ \\
\hline Spouse/partner & $38.9(35)$ & $32.6(28)$ & $35.8(63)$ \\
\hline Parents & $22.2(20)$ & $27.9(24)$ & $25.0(44)$ \\
\hline Other & $25.6(23)$ & $23.2(20)$ & $24.4(43)$ \\
\hline \multicolumn{4}{|c|}{ Mental health now versus a year ago } \\
\hline Better & $73.6(67)$ & $70.6(60)$ & $72.1(127)$ \\
\hline About the same & $23.1(21)$ & $21.2(18)$ & $22.2(39)$ \\
\hline Worse & $3.3(3)$ & $8.2(7)$ & $5.7(10)$ \\
\hline \multicolumn{4}{|c|}{ Age symptoms first noticed (years) } \\
\hline$\leq 10$ & $2.2(2)$ & $2.4(2)$ & $2.3(4)$ \\
\hline $11-19$ & $33.7(30)$ & $25.6(2 I)$ & $29.8(51)$ \\
\hline $20-29$ & $39.3(35)$ & $30.5(25)$ & $35.1(60)$ \\
\hline $30-39$ & $13.5(12)$ & $20.7(17)$ & $17.0(29)$ \\
\hline $40-49$ & $7.9(7)$ & $15.9(13)$ & $11.7(20)$ \\
\hline $50-59$ & $3.4(3)$ & $4.9(4)$ & $4.1(7)$ \\
\hline \multicolumn{4}{|c|}{ Number of years ill (as of survey completion) } \\
\hline$\leq 10$ & $37.1(33)$ & $47.6(39)$ & $42.1(72)$ \\
\hline $11-19$ & $24.7(22)$ & $20.7(17)$ & $22.8(39)$ \\
\hline $20-29$ & $15.7(14)$ & $18.3(15)$ & $17.0(29)$ \\
\hline $30-39$ & $15.7(14)$ & $11.0(9)$ & $13.5(23)$ \\
\hline $40+$ & $6.7(6)$ & $2.4(2)$ & $4.7(8)$ \\
\hline \multicolumn{4}{|l|}{ Age of first treatment (years) } \\
\hline $2-19$ & $18.4(16)$ & $14.5(12)$ & $16.5(28)$ \\
\hline $20-29$ & $39.1(34)$ & $36.1(30)$ & $37.6(64)$ \\
\hline $30-39$ & $18.4(16)$ & $26.5(22)$ & $22.4(38)$ \\
\hline $40+$ & $24.1(21)$ & $22.9(19)$ & $23.5(40)$ \\
\hline \multicolumn{4}{|c|}{ Years between symptoms and first treatment (n) } \\
\hline$<$ I year & $47.7(4 I)$ & $46.8(37)$ & $47.6(79)$ \\
\hline $1-2$ years & $12.8(1 \mathrm{I})$ & $22.8(18)$ & $17.5(29)$ \\
\hline $3-5$ years & $12.8(11)$ & $6.3(5)$ & $9.6(16)$ \\
\hline $6-10$ years & $4.6(4)$ & $10.2(8)$ & $7.2(12)$ \\
\hline $\mathrm{II}+$ years & $22.1(19)$ & $13.9(11)$ & $18.1(30)$ \\
\hline \multicolumn{4}{|l|}{ Have come to accept diagnosis } \\
\hline No & $15.3(13)$ & I5.7 (I4) & $15.5(27)$ \\
\hline Yes & $84.7(72)$ & $84.3(75)$ & 84.5 (I47) \\
\hline
\end{tabular}


Table I (Continued)

\begin{tabular}{|c|c|c|c|}
\hline Characteristic & Bipolar I \% (n) & Bipolar II \% (n) & Total \% (n) \\
\hline \multicolumn{4}{|l|}{ Years between treatment initiation and diagnosis acceptance } \\
\hline Not accepted & $18.4(14)$ & $18.8(13)$ & $18.6(27)$ \\
\hline$<1$ & $27.6(21)$ & $29.0(20)$ & $28.3(4 I)$ \\
\hline $1-5$ & $34.2(26)$ & $33.3(23)$ & $33.8(49)$ \\
\hline $6-10$ & $10.5(8)$ & $11.6(8)$ & $11.0(16)$ \\
\hline $11-15$ & $\mathrm{I} .3(\mathrm{I})$ & $1.5(1)$ & $\mathrm{I} .4(2)$ \\
\hline $16-20$ & $1.3(1)$ & 0 & $1.0(1)$ \\
\hline $21-25$ & $2.6(2)$ & $2.9(2)$ & $2.7(4)$ \\
\hline $25+$ & $3.9(3)$ & $2.9(2)$ & $3.4(5)$ \\
\hline \multicolumn{4}{|l|}{ Hospital use } \\
\hline Ever hospitalized for mental illness or suicide attempt & $67.4(60$ of 89$)$ & $54.7(47$ of 86$)$ & 61.1 (107 of 175$)$ \\
\hline Ever hospitalized in a provincial psychiatric institution & $80.8(42$ of 52$)$ & $79.4(27$ of 34$)$ & $80.2(69$ of 86$)$ \\
\hline Ever hospitalized in a general psychiatric unit & $20.0(10$ of 50$)$ & $17.6(6$ of 34$)$ & $19.0(16$ of 84$)$ \\
\hline Ever committed under provincial mental health legislation & $22.2(12$ of 54$)$ & $16.2(6$ of 37$)$ & $19.8(18$ of 91$)$ \\
\hline \multicolumn{4}{|l|}{ Service use in the last year } \\
\hline Hospitalized as a voluntary patient & $9.4(5$ of 53$)$ & $27.0(10$ of 37$)$ & $16.6(15$ of 90$)$ \\
\hline Hospitalized as an involuntary patient & $3.8(2$ of 53$)$ & $0(0$ of 37$)$ & $2.2(2$ of 90$)$ \\
\hline Use of outpatient community mental health program & $62.0(34$ of 55$)$ & $62.2(28$ of 45$)$ & $62.0(62$ of 100$)$ \\
\hline \multicolumn{4}{|l|}{ Frequency of outpatient treatment $(n=62)$} \\
\hline Weekly & $2.9(1)$ & $10.7(3)$ & $6.6(4)$ \\
\hline $2-3$ times per month & $23.5(8)$ & $17.9(5)$ & $21.0(13)$ \\
\hline Monthly & $38.2(13)$ & $46.4(13)$ & $41.9(26)$ \\
\hline Every $2-3$ months & $35.3(12)$ & $21.4(6)$ & $29.0(18)$ \\
\hline $\mathrm{I}-2$ per year & 0 & $3.6(1)$ & $1.6(I)$ \\
\hline
\end{tabular}

Table 2 Stigma Experiences Scale for patients with bipolar I or II disorder

\begin{tabular}{|c|c|c|c|c|c|c|}
\hline \multirow[t]{2}{*}{ Scale Item } & \multicolumn{2}{|c|}{ Bipolar I $(n=76)$} & \multicolumn{2}{|c|}{ Bipolar II $(n=65)$} & \multicolumn{2}{|c|}{ Bipolar I and II $(n=\mid 4 I)$} \\
\hline & $\%$ endorsed & $\begin{array}{l}\text { Item-rest } \\
\text { correlation }\end{array}$ & $\%$ endorsed & $\begin{array}{l}\text { Item-rest } \\
\text { correlation }\end{array}$ & $\%$ endorsed & $\begin{array}{l}\text { Item-rest } \\
\text { correlation }\end{array}$ \\
\hline $\begin{array}{l}\text { Do you think people will think less of you } \\
\text { if they know you have a mental illness? }\end{array}$ & 52.6 & 0.41 & 46.2 & 0.56 & 49.7 & 0.48 \\
\hline $\begin{array}{l}\text { Do you think that the average } \\
\text { person is afraid of someone with a } \\
\text { serious mental illness }\end{array}$ & 67.1 & 0.29 & 55.4 & 0.50 & 61.7 & 0.39 \\
\hline $\begin{array}{l}\text { Have you ever been teased, bullied, or } \\
\text { harassed because you have a mental illness? }\end{array}$ & 47.3 & 0.21 & 40.0 & 0.65 & 44.0 & 0.41 \\
\hline $\begin{array}{l}\text { Have you felt that you have been treated } \\
\text { unfairly or that your rights have been } \\
\text { denied because you have a mental illness? }\end{array}$ & 38.2 & 0.37 & 35.4 & 0.53 & 36.9 & 0.44 \\
\hline $\begin{array}{l}\text { Have your experiences with stigma } \\
\text { affected your recovery? }\end{array}$ & 32.9 & 0.46 & 41.5 & 0.61 & 36.9 & 0.53 \\
\hline $\begin{array}{l}\text { Have your experiences with stigma } \\
\text { caused you to think less about } \\
\text { yourself or your abilities? }\end{array}$ & 27.6 & 0.43 & 46.2 & 0.55 & 36.2 & 0.47 \\
\hline $\begin{array}{l}\text { Have your experiences with stigma affected } \\
\text { your ability to make or keep friends? }\end{array}$ & 42.1 & 0.55 & 29.2 & 0.35 & 36.2 & 0.45 \\
\hline $\begin{array}{l}\text { Have your experiences with stigma affected } \\
\text { your ability to interact with your family? }\end{array}$ & 44.7 & 0.47 & 49.2 & 0.40 & 46.8 & 0.43 \\
\hline $\begin{array}{l}\text { Have your experiences with stigma affected } \\
\text { your satisfaction with or quality of life? }\end{array}$ & 53.2 & 0.49 & 56.9 & 0.47 & 53.9 & 0.47 \\
\hline $\begin{array}{l}\text { Do you try to avoid situations that may } \\
\text { be stigmatizing to you? }\end{array}$ & 46.1 & 0.42 & 41.5 & 0.29 & 44.0 & 0.35 \\
\hline Kuder-Richardson coefficient of reliability & & 0.72 & & 0.81 & & 0.78 \\
\hline Mean scale score (SD) & & $4.5(2.7)$ & & $4.4(3.0)$ & & $4.5(2.8)$ \\
\hline $95 \% \mathrm{Cl}$ & & $3.9-5.3$ & & $3.7-5.4$ & & $4.0-5.0$ \\
\hline
\end{tabular}

Abbreviations: $\mathrm{Cl}$, confidence interval; SD, standard deviation. 
Table 3 Stigma Impact Scale for patients with bipolar I or bipolar II disorder

\begin{tabular}{|c|c|c|c|c|c|c|}
\hline \multirow[t]{2}{*}{ Scale item } & \multicolumn{2}{|c|}{ Bipolar I $(n=87)$} & \multicolumn{2}{|c|}{ Bipolar II $(n=73)$} & \multicolumn{2}{|c|}{ Bipolar I and II $(n=160)$} \\
\hline & Mean (SD) & $\begin{array}{l}\text { Item-rest } \\
\text { correlation }\end{array}$ & Mean (SD) & $\begin{array}{l}\text { Item-rest } \\
\text { correlation }\end{array}$ & Mean (SD) & $\begin{array}{l}\text { Item-rest } \\
\text { correlation }\end{array}$ \\
\hline \multicolumn{7}{|c|}{ On a scale where 0 is the lowest possible amount and 10 is the highest possible amount, how much has stigma affected you personally? } \\
\hline - Quality of life & $4.7(3.2)$ & 0.73 & $5.0(3.5)$ & 0.78 & $4.8(3.4)$ & 0.75 \\
\hline - Social contacts & $4.1(3.1)$ & 0.74 & $4.6(3.6)$ & 0.76 & $4.3(3.3)$ & 0.75 \\
\hline - Family relations & $4.4(3.6)$ & 0.79 & $4.2(3.7)$ & 0.82 & $4.3(3.7)$ & 0.80 \\
\hline - Self-esteem & $5.2(3.4)$ & 0.71 & $5.2(3.7)$ & 0.56 & $5.2(3.5)$ & 0.63 \\
\hline \multicolumn{7}{|c|}{ On a scale where 0 is the lowest possible amount and 10 is the highest possible amount, how much has stigma affected your family as a whole? } \\
\hline - Quality of life & $3.8(3.3)$ & 0.69 & $3.9(3.5)$ & 0.79 & $3.8(3.3)$ & 0.74 \\
\hline - Social contacts & $3.1(3.0)$ & 0.64 & $2.8(3.2)$ & 0.71 & $3.0(3.1)$ & 0.68 \\
\hline - Family relationship & $3.8(3.3)$ & 0.67 & $3.5(3.5)$ & 0.76 & $3.7(3.4)$ & 0.71 \\
\hline $\begin{array}{l}\text { Cronbach's alpha } \\
\text { reliability coefficient }\end{array}$ & & 0.90 & & 0.91 & & 0.91 \\
\hline Mean scale score (SD) & & $29.1(18.2)$ & & $29.2(20.0)$ & & $29.1(19.0)$ \\
\hline $95 \% \mathrm{Cl}$ & & $25.2-33.0$ & & $24.5-33.7$ & & $26.1-32.1$ \\
\hline
\end{tabular}

Abbreviations: $\mathrm{Cl}$, confidence interval; $\mathrm{SD}$, standard deviation.

with bipolar I (29.1) and bipolar II (29.2) disorder also did not differ significantly $\left(\mathrm{t}_{158}=-0.06, P=0.58\right.$, Table 3$)$.

\section{Comparison between Argentinean and Canadian participants}

There were no differences in gender (Chi-square, $\chi^{2}(1)=0.90$, $P=0.344)$ or marital status $\left(\chi^{2}(1)=0.85, P=0.36\right)$ between Argentinean and Canadian respondents (Table 4). Both populations also showed similar rates of acceptance of their diagnoses $\left(\chi^{2}(1)=0.19, P=0.66\right.$, Table 4$)$ and did not show differences in the number of years between symptoms and first treatment ( $t$-test, $\mathrm{t}_{131}=1.6, P=0.10$, Table 5 ). However, the Argentinean population was significantly younger $\left(\mathrm{t}_{193}=2.1, P=0.04\right)$ and consequently had been ill for less time compared with the Canadian population (mean of 16.3 and 22.8 years, respectively; $\mathrm{t}_{252}=3.9, P<0.001$, Table 5). Argentineans also had a significantly higher level of education $\left(\chi^{2}(3)=32.19, P<0.001\right)$, with $55.7 \%$ having a university education in comparison with $28.6 \%$ in the Canadian population. Respondents in Argentina were also much more likely to be employed (61.3\%) than Canadian $(27.4 \%)$ respondents $\left(\chi^{2}(1)=25.98, P<0.0001\right)$, but interestingly attended outpatient treatment less frequently than the Canadian population $\left(\chi^{2}(5)=29.35, P<0.001\right.$, Table 5). Finally, SES and SIS scores were markedly different between the two populations, with the Argentinean population scoring lower on both the SES (4.5 versus 5.6 in Canadians) and also lower on the SIS (29.1 versus 37.5, Table 6).

To explore more fully any systematic differences in SES and SIS scores between the two patient populations, a twostep forced entry multiple regression was performed. For SES scores, the addition of all variables which differed between the two populations was able to explain $16 \%$ of the variation in SES scores (Table 7). Of these, weekly attendance at an outpatient clinic and the number of years ill were significant predictors of higher SES scores, and having a university level of education showed a near-significant trend (Table 7). The addition of population as a variable (model 2) did not significantly change the predictive power of the model, adding only $1 \%$ to the overall predictive power of model 1 (Table 7).

Table 4 Characteristics of Argentinean and Canadian participants

\begin{tabular}{llll}
\hline & $\begin{array}{l}\text { Argentina } \\
(\mathbf{n = 1 7 4 )}\end{array}$ & $\begin{array}{l}\text { Canada } \\
(\mathbf{n = 8 4})\end{array}$ & $\begin{array}{l}\text { Chi-square analysis } \\
\text { Chi statistic (df), } \mathbf{P} \text { value }\end{array}$ \\
\hline $\begin{array}{l}\text { Gender (\% male) } \\
\text { Highest education }\end{array}$ & 35.6 & 41.7 & $\chi^{2}(\mathrm{I})=0.90, P=0.344$ \\
(\% completed university) & 55.7 & 28.6 & $\chi^{2}(3)=32.19, P<0.001$ \\
Employment (\% employed) & & & $\chi^{2}(I)=25.98, P<0.001$ \\
Marital status (\% married/common law) & 61.3 & 27.4 & $\chi^{2}(I)=0.85, P=0.36$ \\
Frequency of outpatient treatment (\% weekly) & 38.1 & 44.0 & $\chi^{2}(5 *)=29.35, P<0.001$ \\
Diagnosis acceptance (\% accepted) & 6.6 & 46.3 & $\chi^{2}(I)=0.19, P=0.66$ \\
\hline
\end{tabular}

Notes: *The original dataset had six possible answers which were then binned to five by combining "every six months" with "once or twice a year" for Table I. Analysis was done on the six groups. 
Table 5 Characteristics of Argentinean and Canadian participants

\begin{tabular}{|c|c|c|c|}
\hline & \multicolumn{2}{|l|}{ Mean (SD) } & \multirow{2}{*}{$\frac{t \text {-test }}{t \text { statistic (df) }}$} \\
\hline & $\begin{array}{l}\text { Argentina } \\
(n=174)\end{array}$ & $\begin{array}{l}\text { Canada } \\
(n=84)\end{array}$ & \\
\hline Age, years & $42.7(12.6)$ & $45.8(10.3)$ & $\begin{array}{l}t(193)=2.1 \\
P=0.04\end{array}$ \\
\hline $\begin{array}{l}\text { Number of } \\
\text { years ill }\end{array}$ & $16.3(11.9)$ & $22.8(13.3)$ & $\begin{array}{l}t(252)=3.9 \\
P<0.00 I\end{array}$ \\
\hline $\begin{array}{l}\text { Years between } \\
\text { first symptoms } \\
\text { and treatment }\end{array}$ & $4.8(8.1)$ & $6.9(9.9)$ & $\begin{array}{l}t(|3|)=1.6 \\
P=0.10\end{array}$ \\
\hline
\end{tabular}

Abbreviation: SD, standard deviation.

With respect to SIS scores, variance in any of the factors which differed between the two populations led to low predictive power of the model, with these variables explaining only 3\% of the variance in SIS scores (Table 8 ). Adding population in model 2 increased the predictability significantly by $2 \%$, but the overall predictive power remained low at $5 \%$ (Table 8 ).

\section{Discussion}

Patients with bipolar disorder experience stigmatizing events associated with significant psychosocial effects. In this study, we used a questionnaire to assess patients' selfperceived stigma, ie, the ISE. This study validated the ISE in a population of patients with bipolar I or II disorder in Argentina. Cronbach's alpha (SIS) and KR-20 (SES) scores were high at 0.91 and 0.78 , respectively, for all patients with bipolar disorder. This suggests internal consistency and reliability of the scales, because the results are similar to the reliability measures previously found in the Canadian population (Cronbach's alpha $=0.89$ and KR-20 $=0.77$ in patients with bipolar disorder; Cronbach's alpha $=0.91$ and KR-20 $=0.78$ in patients with depression). ${ }^{34}$ The ISE has also been used as a self-assessment measure of stigma in patients with a variety of disorders (schizophrenia, anxiety, bipolar disorder, depression) in Canada, again with high reliability $($ Cronbach's alpha $=0.91, \mathrm{KR}-20=0.83){ }^{4}$

Table 6 Mean SES and SIS scores in Argentinean and Canadian participants

\begin{tabular}{llll}
\hline & $\begin{array}{l}\text { Argentina } \\
\text { Mean (SD; n) }\end{array}$ & $\begin{array}{l}\text { Canada } \\
\text { Mean (SD; n) }\end{array}$ & $\begin{array}{l}\text { Mann- } \\
\text { Whitney U }\end{array}$ \\
\hline SES total score & $4.46(0.24 ; 14 I)$ & $5.80(2.8 ; 79)$ & $\begin{array}{l}U=4 I I 5.0, \\
P=0.00 I\end{array}$ \\
SIS total score & $29.1(19.0 ; 160)$ & $37.5(18.3 ; 57)$ & $\begin{array}{l}U=3483.5, \\
P=0.008\end{array}$ \\
\hline
\end{tabular}

Abbreviations: SES, Stigma Experiences Scale; SIS, Stigma Impact Scale; SD, standard deviation.
The Argentinean population had a lower endorsement of SES questions than the Canadian population, but when asked "Do you think the average person is afraid of someone with a serious mental illness", $61 \%$ of Argentineans answered "yes". Similarly, over half (53\%) of the respondents thought that their experiences with stigma had affected their satisfaction with quality of life. Finally, Argentinean patients with bipolar disorder showed lower scores on the SIS scale, with the highest impact of stigma being on self-esteem (5.2). Cross-cultural differences in the stigma associated with bipolar disorder have been found among European countries, ${ }^{33}$ and here we show differences in stigma when comparing North and South American countries.

There may be several explanations for this finding. Firstly, there may be a sample bias (see Tables 4 and 5, and comments on limitations below), with Argentinean respondents generally having higher education, higher employment rates, attending outpatient clinics less often, and being younger, thus generally being ill for less time. Using a two-step forced entry linear regression, we found that being ill for longer and attending weekly outpatient clinics were significant predictors of higher SES scores, and having a university education also showed a positive trend. Furthermore, age, employment, and education were not significant predictors, and adding population as a factor in a second model did not add significantly more predictive power. Whether weekly outpatient clinic attendance was due to patients feeling stigmatized and needing support, or to some other reason remains to be examined in future studies. These findings suggest that the variables which systematically differed between these two populations were sufficient to predict differences in the SES scores we observed.

With respect to the SIS, none of the factors which differed between the two populations had considerable predictive ability for SIS scores, and addition of population explained a total of just $5 \%$ of the variation. These findings suggest that some other variable(s), perhaps linked to cultural differences, are able to predict SIS scores more accurately than any of the demographic variables which differed between the two populations.

The second potential reason for why we found differences in the SES and SIS scores between the two populations may be couched in terms of differences in family dynamics between modern Canadian and Argentinean societies. That is, the way family members, friends, and relatives act and react towards those with mental illnesses may differ culturally. Specific cultural differences, for example, emotional closeness with family members or 
Table 7 Summary of the two-step forced entry regression analysis examining the role of education, employment, attendance at an outpatient clinic, age, and number of years ill as predictors of Stigma Experiences Scale score differences between Argentinean and Canadian patient populations

\begin{tabular}{|c|c|c|c|c|c|}
\hline Model & Beta & $P$ value & $\Delta \mathbf{R}^{2}$ & $F(d f)$ & $P *$ \\
\hline I. Education (completed university) & 0.12 & 0.09 & 0.16 & $7.66(5204)$ & $P<0.001$ \\
\hline Employment (employed) & -0.11 & 0.12 & & & \\
\hline $\begin{array}{l}\text { Attendance at outpatient clinic } \\
\text { (weekly or more) }\end{array}$ & 0.20 & 0.002 & & & \\
\hline Age & 0.05 & 0.58 & & & \\
\hline Number of years ill & 0.29 & 0.001 & & & \\
\hline 2. Population (Argentina) & -0.10 & 0.20 & 0.01 & $1.633(\mid 203)$ & $P=0.20$ \\
\hline
\end{tabular}

Note: $* p$ value for each regression model.

their supportiveness of mental illness may play a role in predicting SES and SIS outcomes. Future studies could investigate these possibilities and tease out differences by administering additional questionnaires. Notwithstanding, it is important to remember that over half of the Argentinean participants felt that the stigma they experienced had influenced their quality of life, and that their self-esteem had been negatively impacted.

Differences between Argentinean patients with bipolar I and bipolar II disorder were negligible for both SES and SIS, suggesting that stigma affects both equally. This was against our initial prediction that bipolar I disorder would be associated with more stigma as a result of the presence of mixed and manic episodes. Our findings may be the result of the general public's inexperience with the distinctions between bipolar I and II disorder, and this may make it more likely that people will stereotype and discriminate against both as a result. As a prerequisite for inclusion to our study, patients had to be euthymic at the time of testing; however another explanation could be that some patients with bipolar disorder had problems with insight into their illness, in effect not realizing the severity of the stigma they were experiencing during the time of their mixed or manic episodes. Another potential explanation for this finding could be that patients with bipolar I or II disorder consider, at some point, that depressive episodes may produce a higher impact than the euphoric phases of their illness. Thus, it could be that while mood is stable, patients with bipolar I or II disorder viewed themselves as equally stigmatized, even though as shown previously, caregiver stigma is higher for patients with bipolar I than those with bipolar II disorder. ${ }^{15}$

In this study, we used two populations (Argentina and Canada) which differed demographically, and in some instances these differences contributed to the variance observed between the ISE answers for both countries. We were also unable to compare the stigma associated with bipolar I or II disorder in the Argentinean sample with that experienced by the Canadian sample, because the type of bipolar disorder was not reported in the latter. However, our results with regard to the lack of differences in ISE score between patients with bipolar I or II disorder within the Argentinean population are interesting, and the mechanisms and reasons behind this finding deserve further research.

In this vein, future research should focus on patient evaluation during affective episodes in order to measure the potential influence of the emotional, functional, and cognitive

Table 8 Summary of the two-step forced entry regression analysis examining the role of education, employment, attendance at an outpatient clinic, age, and number of years ill as predictors of Stigma Impact Scale score differences between Argentinean and Canadian patient populations

\begin{tabular}{llllll}
\hline Model & Beta & $\boldsymbol{P}$ value & $\Delta \mathbf{R}^{2}$ & $\mathbf{F}(\mathbf{d f})$ & $\boldsymbol{P} *$ \\
\hline I. Education (completed university) & -0.07 & 0.36 & 0.03 & $1.27(5199)$ & \\
Employment (employed) & -0.09 & 0.21 & & \\
Attendance at outpatient clinic & 0.06 & 0.37 & & \\
$\quad$ (weekly or more often) & & & & \\
Age & 0.07 & 0.44 & & $4.76(1198)$ \\
$\quad$ Number of years ill & 0.03 & 0.78 & 0.02 & $P=0.03$ \\
2. Population (Argentina) & -0.19 & 0.03 & & \\
\hline
\end{tabular}

Note: $* p$ value for each regression model. 
impairments produced during the acute phases of the illness on stigma perception.

\section{Conclusion}

This study used the ISE effectively to show that stigma affects the lives of patients with bipolar I or II disorder in Argentina, and has also illuminated this in a Canadian population. ${ }^{34}$ Thus, understanding patient experiences with stigma deserves worldwide attention. What the "Open-the-Doors" program has started is an essential aspect of fighting social stigma around the world, and using tools such as ISE to assess the patient's own perceptions of stigma will undoubtedly help in their long-term efforts. Long-term goals should include validating the ISE in other cultures and other mental illnesses, in order to gain an understanding of individual experiences and the impact of stigma. Work has already started on applying the ISE in an Eastern European population, and it has been used in a study comparing the stigma experienced by patients with bipolar disorder in Argentina, Brazil, and Colombia. ${ }^{31}$ It would also be fruitful to examine stigma in cultures where family groups are very cohesive, and where multiple generations live together; whether more or less social stigma is seen in such societies would be important information to use in future stigma prevention initiatives. It would also be useful to apply the information obtained from the ISE in order to combat social stigma, including implementing educational programs designed for the public, families of patients, and even mental health care professionals, because all three groups have been shown to hold stigmatizing views about patients with mental illness (ie, the public, ${ }^{3,10}$ family members, ${ }^{15}$ and mental health professionals $\mathrm{s}^{9,13,14}$ ). For example, knowing that over half of the patients surveyed feel the general public are afraid of those with mental illnesses, future programs can be geared towards helping the general public in overcoming this fear. By applying the ISE we can reliably ascertain what patients feel with regard to the stigma surrounding their mental illness, and whether these experiences change according to the diagnosis would be of interest. The more knowledge we can glean from patients' experiences and the impact of stigma, the greater the likelihood that stigma mitigation programs can be tailored properly in order to yield maximum benefits.

\section{Acknowledgment}

The authors thank Marianne McGuire for her assistance with preparation of the manuscript.

\section{Disclosure}

The authors report no conflicts of interest in this work.

\section{References}

1. Cooper-Patrick L, Powe NR, Jenckes MW, et al. Identification of patient attitudes and preferences regarding treatment of depression. J Gen Intern Med. 1997;12:431-438.

2. Sirey JA, Bruce ML, Alexopoulos GS, et al. Perceived stigma as a predictor of treatment discontinuation in young and older outpatients with depression. Am J Psychiatry. 2001;158:479-481.

3. Corrigan PW, Watson AC. Understanding the impact of stigma on people with mental illness. World Psychiatry. 2002;1:16-20.

4. Stuart H, Milev R, Koller M. The Inventory of Stigmatizing Experiences: its development and reliability. World Psychiatry. 2005; 4 Suppl 1:33-37.

5. Sartorius N. Stigma and mental health. Lancet. 2007;370:810-811.

6. McNair BG, Highet NJ, Hickie IB, Davenport TA. Exploring the perspectives of people whose lives have been affected by depression. Med J Aust. 2002;176 Suppl:S69-S76.

7. Stuart H. Mental illness and employment discrimination. Curr Opin Psychiatry. 2006;19:522-526.

8. Elgie R, Morselli PL. Social functioning in bipolar patients: the perception and perspective of patients, relatives and advocacy organizations - a review. Bipolar Disord. 2007;9:144-157.

9. Lauber C, Sartorius N. At issue: anti-stigma endeavours. Int Rev Psychiatry. 2007;19:103-106.

10. Angermeyer MC, Matschinger H. Public beliefs about schizophrenia and depression: similarities and differences. Soc Psychiatry Psychiatr Epidemiol. 2003;38:526-534.

11. O’Driscoll C, Heary C, Hennessy E, McKeague L. Explicit and implicit stigma towards peers with mental health problems in childhood and adolescence. J Child Psychol Psychiatry. 2012;53: 1054-1062.

12. Lauber C, Anthony M, Ajdacic-Gross V, Rössler W. What about psychiatrists' attitude to mentally ill people? Eur Psychiatry. 2004;19: 423-427.

13. Nordt C, Rössler W, Lauber C. Attitudes of mental health professionals toward people with schizophrenia and major depression. Schizophr Bull. 2006;32:709-714.

14. Lauber C, Nordt C, Braunschweig C, Rössler W. Do mental health professionals stigmatize their patients? Acta Psychiatr Scand Suppl. 2006;113 Suppl:51-59.

15. Gonzalez JMM, Perlick DA, Miklowitz DJJ, et al. Factors associated with stigma among caregivers of patients with bipolar disorder in the STEP-BD study. Psychiatr Serv. 2007;58:41-48.

16. Hinshaw SP, Cicchetti D. Stigma and mental disorder: conceptions of illness, public attitudes, personal disclosure, and social policy. Dev Psychopathol. 2000;12:555-598.

17. Nilsson KK, Jørgensen CR, Craig TKJ, Straarup KN, Licht RW. Self-esteem in remitted bipolar disorder patients: a meta-analysis. Bipolar Disord. 2010;12:585-592.

18. West ML, Yanos PT, Smith SM, Roe D, Lysaker PH. Prevalence of internalized stigma among persons with severe mental illness. Stigma Res Action. 2011;1:3-10.

19. Brohan E, Elgie R, Sartorius N, Thornicroft G. Self-stigma, empowerment and perceived discrimination among people with schizophrenia in 14 European countries: the GAMIAN-Europe study. Schizophr Res. 2010;122:232-238.

20. Livingston JD, Boyd JE. Correlates and consequences of internalized stigma for people living with mental illness: a systematic review and meta-analysis. Soc Sci Med. 2010;71:2150-2161.

21. Sirey JJA, Bruce ML, Alexopoulos GS, et al. Stigma as a barrier to recovery: Perceived stigma and patient-rated severity of illness as predictors of antidepressant drug adherence. Psychiatr Serv. 2001;52: 1615-1620.

22. Dinos S, Stevens S, Serfaty M, Weich S, King M. Stigma: the feelings and experiences of 46 people with mental illness. Br J Psychiatry. 2004;184:176-181.

23. Wahl OF. Stigma as a barrier to recovery from mental illness. Trends Cogn Sci. 2012;16:9-10. 
24. Sartorius N. Lessons from a 10-year global programme against stigma and discrimination because of an illness. Psychol Health Med. 2006;11: 383-388.

25. Stuart H. Fighting the stigma caused by mental disorders: past perspectives, present activities, and future directions. World Psychiatry. 2008;7: 185-188.

26. Ruiz MÁ, Montes JM, Lauffer JC, et al. Opinions and beliefs of the Spanish population on serious mental illnesses (schizophrenia and bipolar disorder). Rev Psiquiatr Salud Ment (English Edition). 2012;5(2): 98-106.

27. Serafini G, Pompili M, Haghighat R, et al. Stigmatization of schizophrenia as perceived by nurses, medical doctors, medical students and patients. J Psychiatr Ment Health Nurs. 2011;18:576-585.

28. Link BG, Struening EL, Neese-Todd S, Asmussen S, Phelan JC. Stigma as a barrier to recovery: The consequences of stigma for the self-esteem of people with mental illnesses. Psychiatr Serv. 2001;52: 1621-1626.

29. Kessler RC, Merikangas KR, Wang PS. Prevalence, comorbidity, and service utilization for mood disorders in the United States at the beginning of the twenty-first century. Annu Rev Clin Psychol. 2007;3: 137-158.
30. Murray C, Lopez A. Global mortality, disability, and the contribution of risk factors: Global Burden of Disease Study. Lancet. 1997;349: 1436-1442.

31. Vázquez GH, Kapczinski F, Magalhaes PV, et al. Stigma and functioning in patients with bipolar disorder. J Affect Disord. 2011;130:323-327.

32. Hayward P, Wong G, Bright J, Lam D. Stigma and self-esteem in manic depression: an exploratory study. J Affect Disord. 2002;69:61-67.

33. Morselli PL, Elgie R, Cesana BM. GAMIAN-Europe/BEAM survey II: cross-national analysis of unemployment, family history, treatment satisfaction and impact of the bipolar disorder on life style. Bipolar Disord. 2004;6:487-497.

34. Lazowski L, Koller M, Stuart H, Milev R. Stigma and discrimination in people suffering with a mood disorder: a cross-sectional study. Depress Res Treat. 2012;2012:724848.

35. Perlick DA, Rosenheck RA, Clarkin JF, et al. Stigma as a barrier to recovery: adverse effects of perceived stigma on social adaptation of persons diagnosed with bipolar affective disorder. Psychiatr Serv. 2001;52:1627-1632.

36. Brislin R. The wording and translation of research instruments. In: Lonner WL, Berry JW, editors. Field Methods in Cross-Cultural Research. Newbury Park, CA: Sage; 1986.
Neuropsychiatric Disease and Treatment

\section{Publish your work in this journal}

Neuropsychiatric Disease and Treatment is an international, peerreviewed journal of clinical therapeutics and pharmacology focusing on concise rapid reporting of clinical or pre-clinical studies on a range of neuropsychiatric and neurological disorders. This journal is indexed on PubMed Central, the 'PsycINFO' database and CAS.
The manuscript management system is completely online and includes a very quick and fair peer-review system, which is all easy to use. Visit http://www.dovepress.com/testimonials.php to read real quotes from published authors.

\footnotetext{
Submit your manuscript here: http://www.dovepress.com/neuropsychiatric-disease-and-treatment-journal
} 